\section{A MÍDIA IMPRESSA E O POLO AQUÁTICO BRASILEIRO: O MITO DE ALADAR SZABO}

PRINTED MEDIA AND BRAZILIAN WATER POLO: THE MYTH OF ALADAR $S Z A B O$

\author{
LOS MEDIOS IMPRESOS Y EL POLO ACUÁTICO BRASILEÑO: EL MITO DE \\ ALADAR SZABO
}

\section{Silvio de Cassio Costa Telles*, Rômulo Meira Reis ${ }^{\star *}$, Rodrigo Vilela Elias ${ }^{\star \star *}$, Elizabeth Rose Assumpção Harris ${ }^{\star \star * *}$}

Palavras-chave

Esportes.

História.

Mito da

masculinidade.
Keywords

Sports.

History.

Myth of masculinity.

Deportes.

Historia.

Mito de la

masculinidad.
Resumo: Este artigo objetiva analisar a visão da mídia impressa sobre um jogador de polo aquático brasileiro, o húngaro naturalizado Aladar Szabo, e também sobre o polo aquático nos anos 1960. Buscamos identificar como os relatos midiáticos contribuíram para a consolidação da imagem do jogador-mito, como eram relatados os acontecimentos sobre o esporte e ainda de que forma a mídia impressa participou da construção de sua imagem e sua relação com o mito da masculinidade. Metodologicamente, combinamos pesquisa documental e bibliográfica. Verificou-se construção de uma imagem violenta do esporte, aproximando as atitudes e fatos do jogador com o mito da masculinidade.

Abstract: This article looks into the view of printed media on Hungarian-born Braziliannaturalized water polo player Aladar Szabo and also on water polo itself in the 1960s. We sought to identify how media relationships contributed to consolidate the mythical player's image, how sport-related occurrences were narrated, and how printed media participated in the construction of Szabo's image and its relation with the myth of masculinity. Methodologically speaking, we combined documental and bibliographical research. We found the construction of a violent image of the sport, bringing together facts about the player and his attitudes with the myth of masculinity.

Resumen: Este artículo se propone analizar la visión de los medios impresos sobre un jugador de polo acuático brasileño, el húngaro naturalizado Aladar Szabo, y también sobre el polo acuático en los años 1960. Buscamos identificar cómo los relatos hechos por los medios contribuyeron a la consolidación de la imagen del jugador-mito, saber cómo eran relatados los acontecimientos sobre el deporte y de qué forma los medios impresos participaron en la construcción de su imagen y su relación con el mito de la masculinidad. Metodológicamente, combinamos la investigación documental con la bibliográfica. Se constato la construcción de una imagen violenta del deporte, aproximando las actitudes $\mathrm{y}$ hechos del jugador al mito de la masculinidad.
* Universidade do Estado do Rio de Janeiro. Universidade Federal do Rio de Janeiro. Rio de Janeiro, RJ, Brasil. E-mail: silviotelles@ufrj.br

** Universidade do Estado do Rio de Janeiro. Faculdades Integradas Hélio Alonso. Rio de Janeiro, RJ, Brasil. E-mail: romulomreis@bol.com.br

${ }^{\star \star \star}$ Prefeitura Municipal do Rio de Janeiro. Faculdades Integradas Hélio Alonso. Rio de Janeiro, RJ, Brasil. E-mail: rodrigovilelaelias@gmail.com

**** Universidade do Estado do Rio de Janeiro. Rio de Janeiro, RJ, Brasil. E-mail: beth.edfisicaueri@gmail.com

Recebido em: 20-06-2015 Aprovado em: 22-11-2015

(c) (1) (8) Licence 


\section{INTRODUÇÃO}

O polo aquático, apesar de ter conquistado títulos sul-americanos, um panamericano, participado de sete edições dos Jogos Olímpicos, e cumprido um calendário regular de competições regionais, nacionais e internacionais, não se tornou um esporte de massa, nem ganhou uma significativa adesão de participantes ou de espectadores no cenário brasileiro.

Suas origens estão no Rio de Janeiro, quando o polo aquático começou a ser praticado no final do século XIX e início do século XX por remadores de clubes como Flamengo, Boqueirão do Passeio, Natação e Regatas, Guanabara e Vasco da Gama. Como estes atletas eram bastante corpulentos e a natação não era o seu principal esporte, eles utilizavam-se da força para desvencilhar-se de seus adversários, o que gerava certo grau de agressividade. As regras permitiam quase tudo para que se chegasse ao gol, o qual era alcançado quando os jogadores conseguiam colocar a bola dentro de um dos barcos, também utilizados nas regatas, posicionados nos extremos do campo. 0 goleiro ficava em cima deles para saltar sobre 0 atacante, tentando roubar-Ihe a bola. A imagem que ficou do esporte praticado por aqueles remadores era de que jogar polo aquático significava ser viril, forte, valentão e brigão, atributos relacionados ao mito da masculinidade (TELLES, 2002).

Destacamos então a figura de Aladar Szabo, reconhecido como o melhor jogador dos anos 1960 e, para muitos, o ícone do polo aquático brasileiro. Suas características, ou as a ele atribuídas, foram fundamentais para reverberar o estereótipo do esporte. 0 atleta que contribuiu para a construção dessa imagem ainda hoje chama atenção por sua trajetória. 0 projeto "Memória do Esporte Olímpico brasileiro" contemplou em seu concurso em 2013 a produção denominada "Szabo! Em busca do Gol", que teve sua estreia em 20 de dezembro de 2014 na ESPN Brasil. Esse documentário, através de inúmeras entrevistas com jogadores da época, com quem Szabo atuava, apresenta a imagem de um jogador "fora de série" e muito violento que se valia de seu porte físico avantajado para sobrepujar seus adversários (INDIANA PRODUÇÕES CINEMATOGRÁFICAS, 2013).

O crescente desenvolvimento da mídia exerceu e continua exercendo influência nos modos de vida e na formação da opinião da sociedade moderna. No caso do polo aquático, a mídia contribuiu para a construção da imagem violenta do esporte. Como exemplo recente, a série televisiva Malhação em sua sexta temporada apresentou um time de polo aquático que era formado por jovens agressivos que arranjavam confusão constantemente (TELLES, 2009).

Para uma modalidade se desenvolver e permanecer no cenário esportivo de um país é fundamental 0 apoio de suas entidades organizadoras, como confederações e federações. Contudo, a mídia também tem um papel decisivo no tocante à exposição. Quanto mais pessoas entram em contato com o esporte, mais se ampliam as chances do aumento do número de praticantes, potencializando as possibilidades do surgimento de atletas, o que facilita 0 aparecimento de resultados expressivos e de ídolos, determinantes para que haja identificação da sociedade com o esporte.

A década de 1960 é considerada como os anos dourados do polo aquático brasileiro. O país foi representado em três edições dos Jogos Olímpicos, conquistou o único título panamericano em 1963, em São Paulo, e ainda tinha um ídolo, Aladar Szabo. Nenhuma dessas 
situações voltou a acontecer na história desse esporte, nem mesmo isoladamente. Esses três fatores supracitados chamaram a atenção da mídia impressa da época, que contribuiu para difundir o esporte e seu ídolo.

Assim sendo, no presente trabalho o objetivo geral é analisar a visão da mídia impressa sobre o polo aquático e Aladar Szabo nos anos 1960. Como objetivos específicos buscamos identificar/revelar: i) como os relatos da mídia impressa contribuíram para a consolidação da imagem do mito Aladar Szabo; ii) a forma como a mídia impressa relatava os acontecimentos relacionados à modalidade e a Aladar Szabo; iii) a participação da mídia impressa na construção da imagem do jogador de polo aquático e sua relação com o mito da masculinidade.

\section{MÉTODO}

Veyne (1998) nos explica que um acontecimento só tem sentido dentro de uma série, o número de séries é indefinido, elas não seguem um padrão geométrico no qual a lógica sirva para esclarecer definitivamente 0 acontecido. A ideia de história é um limite inacessível, ela é subjetiva e reflete a projeção de nossos valores nas respostas aos questionamentos que decidimos fazer. Descrever a totalidade dos fatos no campo histórico seria uma tarefa impossível, já que um caminho deve ser escolhido, e ele não pode passar por toda parte. Acreditamos ainda que nenhum desses caminhos é o único ou o correto e que, muito menos, reflete na totalidade a história. A história está no conjunto de informações nos cruzamentos dos itinerários possíveis e principalmente nos objetivos propostos. Assim, trata-se de uma pesquisa histórica, em que o período temporal/espacial especificado estabelece o campo, dimensão e inclusive a delimitação em que o estudo se desenvolve.

Visando esclarecer, ampliar e/ou modificar conceitos ou ideias sobre o tema, este estudo caracteriza-se como exploratório (GIL, 1999), sobretudo por possuir poucas abordagens no meio acadêmico e por ser parte da história do polo aquático brasileiro. Diante do exposto, utilizamos como linha de ação uma análise documental associada a uma revisão bibliográfica como estratégia principal (e base de dados) em busca de respostas para os objetivos propostos.

Embora as nomenclaturas sejam similares, os métodos diferenciam-se pela gênese de suas fontes. Desse modo, a pesquisa bibliográfica apresenta fontes secundárias, tais como: livros, revistas/periódicos, leis, anais de congressos, artigos científicos, teses, dissertações, etc. Por outro lado, a pesquisa documental aproveita materiais específicos, como: bancos de dados, entrevistas, relatórios, cartas, fotos, reportagens de jornais, gravações, vídeos, sites, slides ou outros documentos que ainda não receberam tratamento analítico, sempre direcionados a fornecer evidências e/ou justificativas que sustentem as propostas da pesquisa (SÁ-SILVA; ALMEIDA; GUINDANI, 2009).

Assim, margeando os princípios de Sá-Silva, Almeida e Guindani (2009), categorizamos e classificamos o material, delimitando-o pelo período de 1959, cujo marco inicial é a chegada de Aladar Szabo ao Brasil, até sua participação nos Jogos Olímpicos de 1964, em Tóquio'.

1 Durante o estudo foram utilizadas algumas informações de períodos anteriores, como fatos ocorridos nos Jogos Olímpicos de 1932 em Los Angeles e 1956 em Melbourne, que contribuíram para ratificar a hipótese da construção da imagem do jogador de polo aquático no Brasil. 
Conforme exposto no Quadro 1:

Quadro 1 - Fontes bibliográficas e materiais

\begin{tabular}{clc}
\hline Categoria & \multicolumn{1}{c}{ Classificação } & Quantidade \\
\hline \multirow{3}{*}{ Fontes } & Artigos & 3 \\
Bibliográficas & Capítulo de livro & 2 \\
& Dissertação & 1 \\
& Livros & 8 \\
& Total & 14 \\
\hline & Filme/Documentário & 2 \\
& Reportagens do jornal O Globo & 7 \\
& Reportagens do Jornal dos Sports & 7 \\
& Reportagens do Jornal do Brasil & 2 \\
& Reportagens do Correio da Manhã & 2 \\
& Reportagens do Última Hora & 1 \\
& Reportagens do A Gazeta Esportiva & 1 \\
& Reportagens do Diário de São Paulo & 1 \\
& Reportagens do Diário da Noite & 1 \\
& Reportagens do Jornal da Tarde & 1 \\
& Reportagens da Revista do Esporte & 1 \\
& Reportagens de origem desconhecida & 1 \\
& Documentos do COl & 3 \\
& Documentos da FARJ & 1 \\
& Total & 31 \\
\hline
\end{tabular}

Fonte: Elaborado pelo autor

Cabe ressaltar que parte dos documentos citados foi cedida pela família Szabo em visita realizada pelos pesquisadores. Alguns jornais foram disponibilizados por ex-jogadores de clubes do Rio de Janeiro (Fluminense Football Club, Clube de Regatas Guanabara, Botafogo de Futebol e Regatas) que vivenciaram o período selecionado para o estudo. Pela natureza da fonte e estado de conservação, alguns dos jornais não apresentavam número de página, data ou até mesmo o nome.

Para discutir e auxiliar na compreensão do conceito de masculinidade, utilizamos os estudos de Almeida (1995), Gastaldo e Braga (2011), Rial (2000), e Nolasco (1995a, 1995b, 2001), que foram importantes para desvelar as condutas dos jogadores que refletiam um estereótipo, fundamental para manter a característica identitária do grupo de polo aquático.

\section{ALADAR SZABO}

Filho de um pai militar e uma dona de casa, o húngaro Aladar Szabo, nascido em 15 de março de 1933, como muitos jovens da época, sofria pressões familiares sobre seu futuro. O pai desejava que o filho fosse padre e, a mãe, um pianista. Contudo, com o passar do tempo o jovem Szabo se interessava cada vez mais pelas piscinas e menos pela vontade familiar. Com 17 anos deixou de frequentar o seminário e as aulas de piano, mas conquistou o título e recorde europeu juvenil de natação nos 100 metros livres e participava da equipe húngara de revezamento 4x100. Jogando polo aquático em seu time, o Vasas, desde os 15 anos, Szabo apaixonou-se pelo esporte e, em 1952, devido aos seus potentes arremessos, foi convocado para treinar com a seleção húngara (A VIOLENTA..., 1972, p. 4). 
Ao deixar a Hungria em 1956 devido a problemas políticos do país, Szabo fugiu para a Itália, onde encontrou um polo aquático em ascensão, esporte no qual o país havia sido medalha de ouro nos Jogos Olímpicos de Londres (1948) e iria sagrar-se novamente campeão olímpico em Roma em 1960.

Na Itália, seu desempenho nas temporadas de 1957/58, atuando por um time da cidade de Nápoles, o Rari Nantes, fez com que surgissem propostas para jogar em outros países, entre eles o Brasil, que manteve contato com o jogador húngaro nos Jogos Olímpicos de Helsinque em 1952 (VINICIUS..., 1959, p. 5). Nesse contexto, a narrativa do jornal é ratificada por Telles (2009) ao revelar que João Havelange, ex-jogador da seleção brasileira de polo aquático, intermediou a vinda de Szabo para o Brasil, devido à fama do jogador húngaro.

No jornal O Globo (VINICIUS..., 1959, p. 5), Szabo declarou que, além do Brasil, havia recebido convites para integrar equipes na Grécia, na Índia e na Tunísia; mas dois amigos seus, Vinícios e Del Vecchio, jogadores de futebol da equipe do Nápole, falavam tantas maravilhas sobre as belezas naturais do Brasil e de suas lindas mulheres que Szabo optou por aceitar seus conselhos. Além desses fatores, havia uma lei italiana que proibia a participação de estrangeiros nos times locais e como obter um novo visto ou uma naturalização demoraria muito, Szabo decidiu vir para o Brasil.

\subsection{Szabo e sua trajetória no polo aquático brasileiro}

Quando chegou ao Brasil, em 1959, Szabo atuaria como treinador do time de polo do Fluminense, contudo, por ainda apresentar boa condição física, participou desta equipe como jogador entre 1959/61 ajudando o time a se tornar o selecionado que dominou as piscinas cariocas, obtendo um recorde de 104 partidas sem perder entre 1952 e 1961 (NETTO, 1969).

Ao sair do Fluminense, Szabo transferiu-se para o Botafogo em 10 de setembro de 1961 e, no jogo de 21 de outubro do mesmo ano entre estes dois clubes, marcou os dois gols que deram a vitória ao Botafogo. O Fluminense perdeu sua invencibilidade de quase dez anos e terminou por retirar-se da partida (WATER-POLO..., 1961, p. 6). Essa partida foi encerrada prematuramente com briga e confusão depois que a equipe do Fluminense deixou a piscina por sentir-se prejudicada pelo árbitro da partida, Almerídio Brandão. Contudo, mesmo com a derrota, o Fluminense sagrou-se campeão carioca de 1961. Esse histórico jogo foi divulgado em muitas reportagens de jornais da época. Na manchete "Botafogo quebrou invencibilidade do Fluminense: jogo não acabou"- Correio da Manhã, de 1961, o jornal relata a confusão que aconteceu na piscina do Clube de Regatas Guanabara. Cadeiras e mesas foram arremessadas pelos torcedores e atletas, ocasionando o término da partida (BOTAFOGO..., 1961).

Em outra reportagem, "Tempo quente no Guanabara", do Jornal dos Sports, datada do dia 23 de outubro de 1961, são exibidas fotos da briga (87 PARTIDAS, 1961). 0 jornal O Globo em 22 de outubro de 1961 relatava com entusiasmo a derrota do Fluminense para o Botafogo com o título "Vitória sensacional". O periódico ressaltava a brilhante atuação do escrete alvinegro e anunciava um novo reinado nas piscinas (VITÓRIA..., 1961).

Os jornais Última Hora de 23 de outubro de 1961 em sua manchete "Water-Polo: 2 x 0 Botafogo acabou com reinado do tricolor" (WATER-POLO..., 1961) e O Globo "Primeira derrota tricolor em nove anos" (PRIMEIRA..., 1961), do mesmo dia e ano, ressaltam mais a quebra da 
invencibilidade tricolor do que a confusão em si e não deixam de apontar a bela atuação de Aladar Szabo com dois gols.

Nesse acontecimento duas questões são amplamente discutidas. A primeira, a derrota do tricolor das laranjeiras, que se mostrava invencível há quase uma década e, a segunda, a força do ídolo que, ao mudar de equipe, do Fluminense para o Botafogo, foi decisivo na quebra da invencibilidade, dando a essa partida contornos violentos, dramáticos e históricos, atraindo a imprensa e com isso divulgando o esporte e Szabo.

Destaca-se ainda o espaço de que a modalidade dispunha na mídia impressa. Foram muitas reportagens com fotos encontradas nos acervos da família Szabo e de ex-jogadores que demonstravam a importância que o polo alcançava na época, com especial foco para o time tricolor.

- "Fluminense tenta o penta-campeonato"- Jornal dos Sports [1957].

- "Campeão invicto o Fluminense F. C. com 86 partidas"- [1960].

- "86 partidas invictas" Jornal dos Sports - [1960].

• "Campeão pela nona vez o Fluminense" O Globo - [1961].

- "87 partidas invictas" Jornal dos Sports [1960].

- "Flu completou 91 jogos invictos" Jornal dos Sports [1960].

• "Tentará amanhã o Fluminense sua 100ª partida invicta" Jornal dos Sports [1961].

- "Invicto em 101 jogos e penta-campeão do Rio São Paulo o Fluminense" O Globo - [set, 1961].

Em 27 de novembro de 1962, o jornal A Gazeta Esportiva noticiou a vitória de Szabo em um torneio individual de fundamentos. Nessa competição, jogadores do Esporte Clube Pinheiros, Clube Athlético Paulistano, Clube Tietê e o Botafogo Futebol e Regatas se enfrentaram em cinco provas: 50 metros de condução de bola, arremesso de potência, arremesso de precisão, arremesso de penalidades máximas e uma prova de revezamento $10 \times 50$. Das quatro provas individuais, Szabo venceu três e chegou em terceiro na prova de arremesso de precisão. No revezamento, a equipe do Botafogo venceu a disputa. Na contagem final, Szabo obteve 40.8 pontos, mais que o dobro do segundo colocado, Farid Zablith, do Clube Paulistano, com 16 pontos. Essa reportagem demonstra como Szabo encontrava-se em uma condição técnica superior aos jogadores brasileiros, vencendo com facilidade quase todas as provas (POLO AQUÁTICO, 1962).

O apogeu da carreira de Szabo no Brasil aconteceu quando foi convocado para integrar a seleção nacional nos Jogos Pan-americanos de 1963, disputados em São Paulo, e Jogos Olímpicos de Tóquio² em 1964. A presença do húngaro trazia a esperança de que o Brasil pudesse, no Pan-americano, chegar ao título, que desde 1951 era dividido entre EUA e Argentina (TELLES, 2005). Como artilheiro da competição, alcançando a marca de 24 gols, Szabo foi 0 destaque do time brasileiro que conquistou a medalha de ouro. Essa competição foi a primeira a ser organizada pelo Comitê Olímpico Internacional no Brasil e teve relevante repercussão.

Em uma reportagem no jornal Diário de São Paulo do dia 30 de abril de 1963, foi noticiado que os jogos na piscina do Palmeiras ficaram lotados, o que contribuiu ainda mais 
para difundir a modalidade e o nome de seu principal jogador (O BRASIL, 1963). No mesmo ano, o jornal O Globo de 24 de dezembro de 1963 elegeu Aladar Szabo o melhor jogador de polo aquático brasileiro (O GLOBO..., 1963).

Com a presença de Szabo, havia então a expectativa por uma boa participação nos Jogos Olímpicos de Tóquio em 1964. Contudo, mesmo com o ídolo, a seleção brasileira não ultrapassou a primeira fase da competição, assim como ocorrera quatro anos antes, nas Olimpíadas de Roma (COMITÊ OLIMPICO INTERNACIONAL, 1964, SZABO..., 2014).

\section{O POLO AQUÁTICO BRASILEIRO E O MITO DA MASCULINIDADE}

Um fato marcante na história do polo aquático brasileiro que ajuda a ratificar a construção da imagem de violento ocorreu em 1932, durante os Jogos Olímpicos de Los Angeles. Era a segunda participação brasileira nos Jogos e, após perder para a Alemanha, a equipe brasileira saiu da piscina e agrediu o árbitro da partida, Bela Conjadi, sendo então desclassificada (COMITÊ OLIMPICO INTERNACIONAL, 1932). Este episódio provocou um descrédito para o polo aquático na Confederação Brasileira de Desportos (CBD). Sem o apoio dela, o esporte ficou afastado das competições internacionais (TELLES, 2002).

Apesar de ser um esporte de contato, as regras não preveem qualquer tipo de violência, por cima da água ou sob ela, tendo assim os mesmos princípios de outros esportes, como handebol e futebol. $O$ que acontece é a consciência de que ser agredido sem que 0 árbitro perceba gera a possibilidade de um revide sob as mesmas condições e tal circunstância dentro d'água torna a tarefa da arbitragem muito mais difícil.

Rial (2000) já apontava uma intrínseca relação entre masculinidade, resiliência e dor no esporte. A autora explica que, em alguns esportes, existe um aprendizado necessário sobre a incorporação de uma masculinidade. Desta forma, o menino aprende a ser ativo e relativamente agressivo através da inculcação de atitudes que reverberam um conceito de "homem de verdade".

O esporte olímpico, mesmo com as ideias de vanguarda de Coubertin, idealizando uma competição mundial com preceitos de paz e de igualdade, não tinha estímulos à participação feminina. Nos primeiros Jogos Olímpicos da era moderna, que aconteceram em $1896 \mathrm{em}$ Atenas, não foi permitida a participação feminina, o que só ocorreu na segunda edição, em Paris. As mulheres só chegaram a 20\% de participação em relação aos homens em 1972 nas Olimpíadas de Montreal e até 1992 não chegavam a 30\%, o que demonstrava uma supremacia masculina no esporte moderno. Em Pequim 2008, no entanto, foram $42 \%$ de participação feminina, e em Londres 2012, 44\%, demonstrando que um equilíbrio entre a participação de homens e mulheres está próximo (COMITÊ OLIMPICO INTERNACIONAL, 2012).

No polo aquático, esse equilíbrio de gêneros não acompanhou a tendência ao longo do século XX. A participação feminina na modalidade surgiu somente 100 anos depois da primeira competição olímpica masculina em Paris em 1900. Apenas nos Jogos Olímpicos de Sydney em 2000 este esporte contou com a presença de mulheres. A equipe da Austrália sagrou-se a primeira campeã olímpica ao vencer os EUA.

Ainda é possível observar resistência ao fato de mulheres praticarem determinadas modalidades, como futebol, rúgbi e o próprio polo aquático. Os estereótipos e preconceitos, 
mesmo que atenuados, ainda se mantêm vivos em nossos pensamentos. A versão feminina da modalidade começou a ser praticada tardiamente no Brasil, em 1986, na Universidade Federal do Rio de Janeiro, e no mesmo ano em São Paulo, no Clube Atlético Paulistano (TELLES, 2002).

Isso posto, Almeida (1995) aponta uma relação assimétrica entre gêneros, em que existe uma diferença entre eles através de uma espécie de hierarquia como algo classificatório, dando sentido para as pessoas, objetos, atividades, etc. Essa construção serve como pano de fundo para a dominação de um sobre o outro, legitimando espaços, condutas e até esportes como sendo mais masculinos e menos femininos ou vice-versa.

Nesse sentido, Rial (2000) afirma que a presença das mulheres por si só não desmasculiniza de imediato os espaços do esporte, não representando, portanto, uma feminização. A autora explica que a mulher acabava por se contaminar pelo masculino. No entanto, do mesmo modo como ocorreu com o vôlei, o futebol e diversos outros esportes, a presença das mulheres nesses espaços fez com que perdessem o seu caráter de gênero, deixando de ser marcas da masculinidade.

O comparecimento de jogadoras de basquete em revistas tipo Playboy, as fotos de jogadoras de futebol em poses sensuais, tais como as publicadas na revista Placar ou em jornais de circulação nacional, mostram que a habitação desses campos tidos anteriormente masculinos não necessariamente as contamina do masculino aos olhos sociais (RIAL, 2000, p. 253).

Para Nolasco (2001), a masculinidade pode ser buscada de diversas formas. Nas sociedades guerreiras, o vigor físico estava sempre relacionado à força; o seu uso contínuo, excesso e dano eram tidos como referências do valor de um homem. A esses atributos foram atreladas a disciplina e a coragem. Os níveis de tensão experimentados por um homem são convertidos em seu cotidiano, em exigências que, sem controle, poderão levá-lo a buscar cada vez mais formas de escoá-las. Aos meninos é sempre pedido que demonstrem força física, que sejam líderes e estejam preparados para viverem sozinhos. Quando crescem, acabam por acreditar que a tensão é inerente ao estilo de vida do homem, e que a agressividade e a violência são a melhor maneira de expressá-la.

Almeida (1995) ainda realça que a masculinidade permeia um modelo hegemônico dentro da sociedade em que ser homem é provar frequentemente sua coragem e vigor a partir de atitudes e comportamentos vivenciados, aceitando e vencendo desafios como o simples enfrentamento entre meninos. Desta forma, Gastaldo e Braga (2011) evidenciam que em nossa sociedade a aquisição de uma identidade masculina está atrelada à competitividade que é despertada ainda na infância, quando começam as pressões sociais pela afirmação do "ser homem".

Essas afirmações relacionam-se com os embates típicos do esporte, que começam nas escolinhas e categorias de base, onde a disputa pela vitória decorre da submissão do oponente. No polo aquático, por exemplo, desde que se ingressa na modalidade, a luta pelo espaço no meio líquido torna a disputa pela posse de bola ainda mais intensa, necessitando de uma exemplar forma física para suportar tanto o avanço do adversário como a manutenção da cabeça fora d'água.

Gastaldo e Braga destacam o versus, a luta e a competitividade no campo masculino:

A prática de disputas e competições pode ser considerada uma característica bastante generalizada do ethos masculino, sendo um tema recorrente de pesquisas na área de ciências humanas. Em culturas as mais diversas, a afirmação social do 
'ser homem' passa pela disputa com outros homens, seja do modo mais direto, em uma luta corpo a corpo, seja por vias mais sutis, como desafios verbais, torneios de insultos ou apostas em rinha de galos (GASTALDO; BRAGA, 2011, p. 880).

De acordo com Nolasco (1995a), os padrões tradicionais consolidados pelo modelo patriarcal exigem sempre uma relação de confronto: um ataca, outro defende; alguém ganha, outro perde. Com essa perspectiva de relação, estabelece-se uma intrínseca aproximação com a competitividade, criando-se a crença de que tomar atitudes combativas e agressivas é característica própria dos homens.

Concordamos com Rial (2000) quando a autora mostra que a masculinidade que se constrói no esporte difere conforme a modalidade praticada. No boxe ou no rúgbi, há um ethos específico que representa tanto a construção histórica do esporte como também nas características físicas dos atletas. Assim sendo, ser másculo dentro do polo aquático pode ou não desenvolver as mesmas atitudes no atletismo, mas a virilidade é uma marca a ser seguida/ desenvolvida em esportes que notadamente tenham históricos muito masculinizados.

Portanto, ser forte, ser viril e ser "homem" são características valorizadas para que 0 jogador construa com mais facilidade sua identidade e atinja seus objetivos dentro do esporte. Nesse sentido, podemos inferir que existe uma relação de proximidade do polo aquático com 0 mito da masculinidade, definido por Nolasco (1995a).

\section{A MÍDIA E A CONSTRUÇÃO DO MITO}

A performance de Szabo como jogador, comentada pela mídia, demonstra relação com as características apontadas sobre a masculinidade que ajudaram a criar/manter o estereótipo do "jogador de polo aquático". Nesta parte do estudo, veremos como essas representações vão se encaixando dentro do perfil de Szabo, tornando-o um ícone e um exemplo do mito da masculinidade.

Muitas vezes, quando usamos a palavra mito, emprestamos a ela um significado de mentira, de falácia: "isso não é verdade, é um mito". No entanto, o mito corresponde à crença de um povo, do conjunto, da comunidade, da coletividade e por isso, ele se torna verídico para o povo que o reconhece. A pessoa que encarna um mito afasta-se do comum, dos mortais. 0 mito sobrevive num povo não por ser a verdade, mas por refletir um aspecto real desse mesmo povo e até de todos nós (FEIJÓ, 1995). Aladar Szabo encarna o mito da masculinidade e se apresenta como um modelo para aqueles que desejam tornar-se parte integrante do grupo de jogadores.

O estereótipo viril e violento do jogador de polo aquático fazia-se presente na maioria das vezes em que era apresentada alguma notícia sobre o esporte. Tal característica potencializava a imaginação daqueles que não vivenciavam o esporte e apenas escutavam as notícias, como no exemplo do jornal O Globo de 22 de outubro de 1961, sobre o histórico jogo entre Botafogo e Fluminense. É interessante comentar que nesta reportagem o autor relata que não esteve presente na partida, mas pela imagem que o polo aquático remetia, ele imaginava como as coisas teriam acontecido.

Water Polo é um esporte engraçado: por cima d’água tudo é muito tranqüilo, mas por baixo os jogadores usam mais as pernas para darem sarrafadas com mais violência que o Joubert. [...] De vez em quando o juiz pára a partida para contar os jogadores, e 
sempre faltam alguns. Aídesce um escafandrista para recolher os corpos estraçalhados. [...] E sabe lá o que é levar uma 'gravata' dentro d'água? Glub! Glub! Glub! [...] E é um tal de rasgar calção que não acaba mais! Que vexame! As rouparias dos clubes fornecem durante um jogo uns oitenta, para cada craque. É por isso que o São Cristóvão não disputa o campeonato de Water Polo. (SÃO JANUÁRIO, 1961, p. 6)

Szabo, em certos momentos, nutria esta imagem que a esse esporte havia sido dada. Em 20 de abril de 1972, o Jornal da Tarde apresentava reportagem em que Szabo dizia bater quando perdia a paciência em alguma discussão. O sucesso e o talento do jogador, porém, não eram esquecidos e na mesma matéria o repórter referia-se a ele como o Pelé do polo aquático (A VIOLENTA..., 1972).

Em reportagem do Jornal do Brasil de 14 de outubro de 1982, dois dias após a morte de Szabo, intitulada "Era bom de bola e de briga", fica clara a tentativa de relacioná-lo com uma imagem de violento. Vinte anos depois do fatídico jogo contra o Fluminense em que Szabo fez dois gols e a partida não acabou, o jornal relembrava a atitude do jogador, que, segundo a reportagem, teria brigado dentro e fora da piscina, destacando ainda a quebra de dentes e costelas de jogadores adversários em outros momentos (ERA BOM DE BOLA..., 1982).

Juntamente com um nível técnico superior ao dos brasileiros, a constituição física de Szabo contribuiu para criar a mítica ao seu redor. As jogadas mais viris que o envolviam ganhavam grandes proporções. Um incidente envolvendo o jogador Álvaro Pires, do Fluminense, foi relatado das seguintes maneiras: "Szabo se defende: cotovelada em Álvaro foi acidente" (SZABO..., 1962, p. 5). "Agressão e Sangue na Piscina" (AGRESSÃO..., 1962, p. 8).

Nas reportagens, Szabo dizia que a cotovelada tinha sido um acidente e que não houve intenção de ferir o adversário. Entretanto, Álvaro Pires desmaiou, perdeu dentes e passou por cirurgia no rosto. Szabo acusava ainda a repercussão do episódio, reclamando que tudo não passava de uma jogada do Fluminense, seu ex-clube, para atrapalhar sua carreira e participação na seleção brasileira.

As reportagens "Crise na seleção nacional: Técnico e jogadores recusaram" (CRISE..., 1962, p. 4) e "Estúpido o que pretendem com Szabo" (ESTÚPIDO..., 1962) apontam que havia um movimento no sentido de punição contra Szabo pelo ocorrido com o jogador do Fluminense. O conselho técnico da CBD havia votado pela não convocação de Szabo para o sul-americano na cidade de Antofagasta, no Chile. Contudo, os jogadores e o técnico da seleção se opuseram a essa medida, pois sabiam que sem a presença do ídolo as pretensões da equipe seriam reduzidas. $\mathrm{Na}$ mesma reportagem se cogita ainda uma expulsão do país como pena para o jogador.

Ao final do imbróglio, nada aconteceu com Szabo e a reportagem com título "Szabo será convocado pela CBD: maioria aprova, mas há reação" (SZABO..., 1962), explica que Szabo seria convocado mesmo sabendo que alguns seriam contra, principalmente os dirigentes. Com a presença de Szabo, o Brasil conquistou o sul-americano de 1962, retirando da Argentina uma hegemonia que durava três competições (TELLES, 2005).

Percebe-se que a fama de violento e os episódios que realçam a força física só contribuíram para justificar a representação masculinizada do polo aquático brasileiro. Essa imagem é reforçada e representada através de Szabo, que encarnaria o mito da masculinidade.

Como acontece com diversos ídolos, após sua morte, surgem homenagens relembrando frases, entrevistas e características específicas que mantêm a memória do jogador viva 
naquele meio esportivo. Em 1985, um material de divulgação distribuído pela Federação Aquática do Rio de Janeiro (FARJ) ressaltava uma frase do jogador, na qual o jogo de polo era comparado à guerra. Essa maneira do jogador encarar o esporte aproxima-o ainda mais do mito da masculinidade e nos remete a situações em que o esporte representou as guerras (FEDERAÇÃO AQUÁTICA DO RIO DE JANEIRO, 1985).

No polo aquático, especificamente, em 1956, na fase final dos Jogos Olímpicos de Melbourne, a partida de polo entre Hungria e URSS ficou conhecida como o jogo da piscina sangrenta. Sobre esse episódio, foi feito um filme em 2006, intitulado "Children of Glory", cuja tradução para o português, "Sangue nas águas", dinamizou a força simbólica de uma "batalha" esportiva.

A película foi dirigida pela húngara Krisztina Goda como parte das atividades que recordavam os 50 anos de uma revolta no país contra a dominação soviética, que foi brutalmente reprimida. A imagem de um jogador húngaro saindo da água ensanguentado e divulgada por todo o mundo marca não só os Jogos de Melbourne, mas a própria memória coletiva húngara sobre o evento (CABO, 2011). Além desse exemplo, podemos citar o boicote dos países capitalistas aos Jogos Olímpicos de Moscou em 1980 e o boicote dos países socialistas aos Jogos Olímpicos de Los Angeles, em 1984.

Segundo Nolasco (1995b), a guerra nos mostra que a irracionalidade masculina, travestida em juízo moral, ganha espaço na consciência dos homens, fazendo-os desempenhar o papel mais radical de sua identidade social. Portanto, o compromisso individual com a agressão e a violência redunda no investimento social em direção às guerras, o que nos leva a pensar em um tipo de pressão que os homens exercem sobre suas próprias subjetividades, assim como ocorreu com o polo aquático em 1956.

\section{CONSIDERAÇÕES FINAIS}

Ser forte, ser viril e ser "homem" são características valorizadas para que o jogador construa com mais facilidade sua identidade e atinja seus objetivos dentro do esporte. Além disso, a presença de um ídolo ratifica e exemplifica o modelo a se seguir.

Os anos de 1960 foram singulares para o polo aquático nacional. Participamos dos Jogos Olímpicos de 1960, 1964 e 1968 e conquistamos o título nos Jogos Pan-Americanos de São Paulo em 1963, o que disseminou uma grande quantidade de notícias sobre um esporte vencedor, que antes destes fatos não eram comuns. Tudo isso foi incrementado por um craque das piscinas, o húngaro Aladar Szabo, que se configurou como protagonista desse momento. A tríade resultados, ídolo e mídia, combinação significativa para o crescimento de qualquer esporte, nunca mais voltou a acontecer na história dessa modalidade.

O desempenho de Szabo como jogador comentado pela mídia demonstra a relação com as características apontadas sobre a masculinidade que ajudaram a criar/manter 0 estereótipo do "jogador de polo aquático". A mídia escrita ajudou também a disseminar uma visão masculinizante do esporte, enaltecendo brigas, histórias e jogos que representavam e buscavam ratificar a imagem truculenta dos jogadores.

As reportagens chamavam a atenção para a faceta viril da modalidade, e a imagem e fama de Aladar Szabo serviam de chamariz para atrair leitores. Esse discurso midiático da 
época marcou sobremaneira o esporte no Brasil, sendo que o polo aquático ainda é retratado em outras formas de mídia, como a televisiva, como violento.

Apesar de compreender que a violência é uma categoria relacional e que há uma construção midiática sobre uma representação de violência para com o esporte, o modelo de jogo ambientado neste estudo favorecia que os "de fora" tivessem a visão de uma modalidade de difícil prática, devido ao exacerbado contato físico e à pouca mobilidade dos jogadores, já que, diferentemente de hoje, tinham posições fixas na piscina, o que facilitava o acontecimento de jogadas viris.

Atualmente, a característica do jogo é outra. É preciso muita velocidade e aceleração, pois o tempo de posse bola não ultrapassa 30 segundos e não há muito espaço para intensos contatos físicos na maioria das posições, proporcionando uma partida mais dinâmica e, aos olhos dos "de fora", mais fluida. Sobre o futuro da imagem desse esporte, somente o tempo nos mostrará se essas mudanças inseridas no jogo surtirão efeito nas novas manchetes midiáticas.

\section{REFERÊNCIAS}

AGRESSÃO e sangue na piscina. Revista do Esporte, [Rio de Janeiro?], p. 8, 20 jan. 1962.

ALMEIDA, Miguel Vale de. Senhores de si: uma interpretação antropológica da masculinidade. Lisboa: Fim de Século, 1995.

BOTAFOGO quebrou invencibilidade do Fluminense: jogo não acabou. Correio da Manhã, Rio de Janeiro, p.8, 22 Out. 1961.

O BRASIL isola-se na liderança do Polo Aquático. Diário de São Paulo, São Paulo, p. 7, 30 abr. 1963.

$\mathrm{CABO}$, Álvaro do. É só um jogo, pelo menos por enquanto. A semifinal de pólo aquático Hungria $x$ URSS nas Olimpíadas de Melbourne e o contexto político húngaro em 1956. Recorde, Revista de História do Esporte, Rio de Janeiro, v. 4, n. 1, p. 1-14, jun. 2011.

CAMPEÃO invicto o Fluminense F. C. com 86 partidas. Rio de Janeiro,1960.

CAMPEÃO pela nona vez o Fluminense. 0 Globo, Rio de Janeiro, 1961.

COMITE OLÍMPICO INTERNACIONAL. First-ever Olympic Medals awarded to women boxers. 10 Ago. 2012. Disponível em: <http://www. olympic.org/news/first-ever-olympic-medals-awarded-to-womenboxers/17192>. Acesso em: 23 out. 2015.

COMITÊ OLÍMPICO INTERNACIONAL. Olimpiade. Los Angeles: Comitê Olímpico Organizador; 1932. COMITÊ OLÍMPICO INTERNACIONAL. XVIII Olimpíada. Tóquio: Comitê Olímpico Organizador, 1964.

CRISE na seleção nacional: técnico e jogadores recusaram. Jornal dos Sports, Rio de Janeiro, p. 4, 1962.

ERA BOM DE BOLA e de briga. Jornal da Tarde, Rio de Janeiro, p. 6, 14 out. 1982.

ESTÚPIDO o que pretendem com Szabo. Diário da Noite, Rio de Janeiro, 1962.

FEDERAÇÃO AQUÁTICA DO RIO DE JANEIRO. II Copa Sears Rio PA. Rio de Janeiro: FARJ; 1985.

FEIJÓ, Martin Cezar. O que é herói. São Paulo: Brasiliense, 1995.

FLU COMPLETOU 91 jogos invictos. Jornal dos Sports, Rio de Janeiro, 1960.

FLUMINENSE tenta o penta-campeonato. Jornal dos Sports, Rio de Janeiro, 1957. 
GASTALDO, Édison Luis; BRAGA, Adriana Andrade. Corporeidade, esporte e identidade masculina. Estudos Feministas, Florianópolis, v. 19, n. 3, p. 875-893, set./dez. 2011.

GIL, Antônio Carlos. Métodos e técnicas de pesquisa social. 5. ed. São Paulo: Atlas, 1999.

O GLOBO apresenta: os melhores do ano. O Globo, Rio de Janeiro, p. 4, 24 dez. 1963.

INDIANA PRODUÇÕES CINEMATOGRÁFICAS. SZABO em busca do gol! Rio de Janeiro: 2013. Disponível em: <http://memoriadoesporte.org.br/2013/11/28/vencedores-do-edital-2013/> Acesso em: 23 Out. 2015.

INVICTO em 101 jogos e penta-campeão do Rio-São Paulo o Fluminense. 0 Globo, Rio de Janeiro, set. 1961.

NETTO, Paulo Coelho. História do Fluminense. Rio de Janeiro: FFC, 1969. v. 2: 1952 a 1968.

NOLASCO, Sócrates. A desconstrução do masculino. Rio de Janeiro: Rocco, 1995b.

NOLASCO, Sócrates. De Tarzan a Homer Simpson. Rio de Janeiro: Rocco, 2001.

NOLASCO, Sócrates. 0 mito da masculinidade. Rio de Janeiro: Rocco, 1995a.

86 PARTIDAS invictas. Jornal dos Sports, Rio de Janeiro, p. 7, 1960.

87 PARTIDAS invictas. Jornal dos Sports, Rio de Janeiro, 1960.

POLO AQUÁTICO: coroado de êxito o torneio individual. A Gazeta Esportiva, São Paulo, p. 5, 27 nov. 1962.

PRIMEIRA derrota tricolor em nove anos. 0 Globo, Rio de Janeiro, p. 4, 23 out. 1961.

RIAL, Carmen Silva. Rúgbi e judô: esporte e masculinidade. In: PEDRO, J.M.; GROSSI, M.P. (Org.). Masculino, feminino, plural: gênero na interdisciplinaridade. 2. ed. Florianópolis: Ed. Mulheres, 2000. p. 229-258.

SÃO JANUÁRIO, Zé de. Water-polo: cadáver em decomposição. O Globo, Rio de Janeiro, p. 6, 22 out. 1961.

SÁ-SILVA, Jakson Ronie; ALMEIDA, Cristóvão Domingos de; GUINDANI, Joel Felipe. Pesquisa documental: pistas teóricas e metodológicas. Revista Brasileira de História \& Ciências Sociais, Porto Alegre, p. 1-15, n. 1, 2009.

SZABO em busca do gol. Direção, roteiro, entrevistas e edição: Marcos Ribeiro. Produção executiva: Marco Altberg. Produção: Monique Nóbrega. Música: Antônio Saraiva. Narração: Gustavo Gasparini. Pesquisa: João Luis Ribeiro. 2014. DVD (27 min.), cor. Produzido por Indiana Produções Cinematográficas.

SZABO se defende: cotovelada em Álvaro foi acidente. Jornal do Brasil, Rio de Janeiro, p. 5, 4 jan. 1962.

SZABO será convocado pela CBD: maioria aprova, mas há reação. Correio da Manhã, Rio de Janeiro, 1962.

TELLES, Silvio de Cássio Costa. Aladar Szabo e o polo aquático brasileiro: Uma contribuição para construção da identidade do esporte. In: CONGRESSO BRASILEIRO DE CIÊNCIAS DO ESPORTE, 16., CONGRESSO INTERNACIONAL DE CIÊNCIAS DO ESPORTE, 2009, Salvador. [Anais...] Disponível em:<http://congressos.cbce.org.br/index.php/conbrace2009/XVI/paper/view/616/829>. Acesso em: 20 maio 2015.

TELLES, Silvio de Cássio Costa. A identidade do jogador de polo aquático e o mito da masculinidade. 2002. 82f. Dissertação (Mestrado) - Programa de Pós-Graduação em Educação Física, Universidade Gama Filho, Rio de Janeiro, 2002.

TELLES, Silvio de Cássio Costa. Polo aquático. In: COSTA L. Atlas do Esporte no Brasil: atlas do esporte, educação física e atividades físicas de saúde e lazer no Brasil. Rio de Janeiro: Shape, 2005. 
TEMPO QUENTE no Guanabara. Jornal dos Sports, Rio de Janeiro, p. 5, 22 out. 1961.

TENTARÁ amanhã o Fluminense sua 100르 partida invicta. Jornal dos Sports, Rio de Janeiro, 1961.

VEYNE, Paul. Como se escreve a história e Foucault revoluciona a história. Brasília: Ed. UnB, 1998.

VINICIUS e Del Vecchio fizeram Szabo se enamorar do Brasil. 0 Globo, Rio de Janeiro, p. 5, 30 maio 1959.

A VIOLENTA história de Szabo. Jornal da Tarde, Rio de Janeiro, p. 4, 20 abr. 1972.

VITÓRIA Sensacional. O Globo, Rio de Janeiro, p. 6, 22 out. 1961.

WATER-POLO: 2 x 0. Botafogo acabou com reinado do tricolor. Última Hora, Rio de Janeiro, p. 6, 23 out. 1961. 